AperTO - Archivio Istituzionale Open Access dell'Università di Torino

\title{
Pulmonary Echinococcosis or Lung Hydatidosis: A Narrative Review
}

\section{This is a pre print version of the following article:}

Original Citation:

Availability:

This version is available http://hdl.handle.net/2318/1785586

since 2021-04-14T14:33:35Z

Published version:

DOI:10.1089/sur.2020.197

Terms of use:

Open Access

Anyone can freely access the full text of works made available as "Open Access". Works made available under a Creative Commons license can be used according to the terms and conditions of said license. Use of all other works requires consent of the right holder (author or publisher) if not exempted from copyright protection by the applicable law. 
Title: Pulmonary Echinococcosis or Lung Hydatidosis: a Narrative Review

Running Title: Pulmonary Echinococcosis

Tommaso Lupia ${ }^{1 \#}$, Silvia Corcione ${ }^{1}$, Francesco Guerrera ${ }^{2}$, Lorena Costardi ${ }^{2}$, Enrico Ruffini ${ }^{2}$, Simone Mornese Pinna ${ }^{1}$ and Francesco G. De Rosa ${ }^{1}$

\section{Affiliations:}

${ }^{1}$ Department of Medical Sciences, Infectious Diseases, University of Turin, Turin, Italy.

${ }^{2}$ Department of Surgical Sciences, Università degli Studi di Torino, Turin, Italy

\section{\#Corresponding author:}

Tommaso Lupia, MD

Department of Medical Sciences, Infectious Diseases

University of Turin, Italy

Email: tommaso.lupia89@gmail.com 


\begin{abstract}
Background

Lung hydatidosis is a zoonosis related to infection by the Echinococcus tapeworm species. Lung involvement in this condition is second only to the liver Echinococcosis. Diagnosis commonly results from an incidental finding in a routine X-ray evaluation because of the delayed growth of the cysts. Moreover, a uniform treatment regimen or approach may not be feasible because of the variability of pulmonary echinococcosis. In this narrative review we aimed to summarize the main features of lung hydatidosis with a perspective on medical and surgical treatment.
\end{abstract}

\title{
Methods
}

A literature search was performed using the PubMed database and the Cochrane library. Search terms included "pulmonary echinococcosis" and "lung hydatidosis". The MeSH terms were "lung" [All Fields] AND \{“echinococcosis" [MeSH Terms] OR ("hydatidosis" [All Fields] OR "pulmonary" [All Fields] AND "echinococcosis" [All fields] OR "hydatidosis". A search period of September 1980 to May 2020 was selected to compare studies from different decades, given the changes in pulmonary echinococcosis management.

\section{Results}

A uniform treatment regimen or approach may not be feasible because of the variability of pulmonary echinococcosis. No clinical trials have compared all the different treatment modalities. Cyst size, characteristics, position in the lung and clinical presentation and the availability of medical/surgical expertise and equipment are the mainstays of echinococcosis management. When feasible, surgery is still the main therapeutic option to remove the cysts; antiparasitic drugs may minimize complications during high-risk surgery or be used as a definitive therapy in certain cases with major contraindications to surgery.

Conclusions

Lung hydatidosis management must become less heterogeneous. We support treatment targeted to the individual on the basis of the clinical situation, host factors and surgical risk. Strict cooperation in this process between infectious disease specialists and surgeons may optimise best practices to help create shared practical guidelines to simplify clinicians' decision-making. 


\section{Introduction}

Human pulmonary echinococcosis is a zoonotic disease related to infection by the Echinococcus tapeworm species [1]. Lung involvement in this condition is epidemiologically secondary only to liver disease and has been found in about 20\% of infected patients [2]. Most cases of echinococcosis are related to Echinococcus granulosus [3], and human infection is widespread and considered a significant public health issue in countries where dogs, the main definitive hosts, live in close contact with humans and livestock [4]. Diagnosis commonly results from an incidental finding in a routine X-ray evaluation because of the delayed growth of the cysts, becoming symptomatic with the rupture of the cysts and occasionally with the development of immune-mediated reactions against Echinococcus spp. [1-2, 4]. A uniform treatment regimen or approach may not be feasible because of the variability of pulmonary echinococcosis [4-5]. Notwithstanding its frequency and widespread endemicity, the knowledge of and literature on lung hydatidosis must be expanded. Furthermore, a standard of care has not been widely endorsed or implemented outside referral centres [1-2, 4-5]. We aimed to summarize the main features of and evidence on lung hydatidosis from the perspective of medical and surgical treatment.

\section{Methods}

A literature search was performed using the PubMed database and the Cochrane library. Search terms included "pulmonary echinococcosis" and "lung hydatidosis". The MeSH terms were "lung" [All Fields] AND [ "echinococcosis" [MeSH Terms] OR ("hydatidosis" [All Fields] OR "pulmonary" [All Fields] AND “echinococcosis" [All fields] OR "hydatidosis". A search period of 1 September 1980 to 1 April 2020 was selected to narratively review studies from different decades, given the changes in pulmonary echinococcosis management.

\section{Epidemiology}

Human echinococcosis is widespread throughout the world and has some peculiarity between cystic and alveolar echinococcosis (CE and AE, respectively) [6-7]. E. vogeli and E. oligarthra, belonging to the so-called neotropical type of echinococcosis, are limited to South America, and new cases are rarely reported [8-10]. Thompson and Lymbery (1988) suggested the presence of intraspecific variants of $\mathrm{CE}$ and introduced the concept of E. granulosus sensu lato complex [11]. The latter includes genotypes from G1 to G10 (with the uncertain existence of G9), subdivided according to mitochondrial DNA sequences (mtDNA). Its taxonomy merges the genotypes into five species: $E$. granulosus sensu stricto (G1, G2 and G3), Echinococcus equinus (G4), Echinococcus ortleppi (G5), Echinococcus canadensis (G6, G7, G8 and G10) and Echinococcus felidis [2]. According to a recent 
summary of 1,661 genotyped cases published worldwide, the majority are caused by E. granulosus sensu stricto [2]. Molecular identification of human CE cases is strongly recommended for a better understanding of the epidemiology, pathology and natural history of infection, particularly in areas of sympatry, where multiple etiological agents of CE exist [2]

\section{Cystic Echinococcosis (CE)}

Attempts to map the incidence and prevalence of CE in humans have found a lack of accurate case records [3]. For example, the European registry of CE (ERCE) was recently launched [12], born of the Human cystic Echinococcosis ReseArch in CentraL and Eastern Societies (HERACLES) project [13]. Most of the available data concerned cases transmitted by domestic intermediate hosts [3]. Nevertheless, with the above limits, CE's epidemiology seems to be stable in the last 20 years, and the latest estimate of the global burden of CE is 188,000 new cases per annum [3]. Eastern China, Central Asia, South America, the Mediterranean and eastern Africa are endemic areas [3, 14-19]. CE has been declared eliminated from New Zealand, and some regions of Australia, such as Tasmania, have been provisionally declared free of the disease in humans [1,20] although it is still found in Tasmanian wild and rural dogs [20]. In Western Europe [21] and North America [22], CE is not considered a significant cause of morbidity or mortality, and most human cases are imported, although an autochthonous cycle with low prevalence is present. Sporadic cases in the USA were reported by Moro et al. [22] in Alaska, California and Utah. In northern Europe, the United Kingdom is endemic for E. granulosus with the highest incidence in the western isles, Shetland and Highlands, while Ireland is believed to be nonendemic for CE [21]. In southern Europe, which includes Portugal, Spain, France, Greece and Italy, CE is the most critical helminth zoonosis, with a life cycle involving dogs and farm livestock as definitive and intermediate hosts, respectively [21].

\section{Alveolar Echinococcosis (AE)}

Although AE is generally considered a parasite of the northern hemisphere, the criteria for designation of a region as endemic for E. multilocularis have not been consistently defined, largely due to marked global differences in surveillance efforts and sensibility of diagnostic tools, as well as variability in host assemblages and host prevalence [23]. The global annual incidence of AE is estimated to be 18,200 cases, $91 \%$ of which occur in China, notably on the Tibetan plateau [24]. AE is also endemic in Central Asia, and both E. multilocularis and E. granulosus are highly represented in Kazakhstan and Kyrgyzstan [24-25]. Human cases of E. multilocularis have recently been found in European countries previously considered to be free of AE, for example, in the previously unrecognized areas of endemicity of France, Switzerland, Germany, and Austria [26-29]. Currently, approximately 1600 new cases of AE have been reported in Europe up to 2019 [24]. AE had not been considered a major 
human health issue in North America, except in Alaska, until recently, and E. multilocularis has not been reported in Mexico or the southern United States [24, 30].

\section{Life Cycle}

Hosts for the cestodes tapeworm may be subdivided into three categories: definitive, intermediate and accidental [31]. The definitive hosts are carnivores, notably dogs, cats and wild canids, in which adult tapeworms (2.0-7.0 mm length for E. granulosus and 1.2-4.5 mm for E. multilocularis) inhabit the small intestine [31-33]. Domestic animals and other warm-blooded vertebrates, such as sheep, goats, cattle, horses, camels and pigs, act as intermediate hosts, ingesting eggs released by carnivores; they carry predominantly Echinococcus granulosus. Rodents, deer, moose, reindeer and bison are intermediate hosts of E. multilocularis [34-37]. Humans may accidentally act an intermediate host although they do not have a clear role in the biological cycle [34-37] (Figure 1).

A complete life cycle takes four to seven weeks. In the small intestine of definitive hosts, cestodes scolex present a double row of hooklets, which play a pivotal role in the attachment to the intestinal mucosa. Cestodes scolex have at least two proglottids (the number of proglottids changes between causative agents, from three to six in E. granulosus and from two to six in E. multilocularis), which contain numerous eggs. The eggs are passed out through the host's faeces and released into the environment [31].

The intermediate hosts ingest the eggs while feeding, which settle in their gut and release oncospheres that are subsequently transported through the blood or lymph to primary target organs. Lymph enters the portal circulation via the intestinal wall and travels to the visceral organs' capillary bed (primarily the liver, secondarily the lungs) [36-37]. In the organs, oncospheres become vesicles (metacestodes) and grow concentrically into a fluid-filled cyst. Hydatic cysts for E. granulosus are initially fluid filled, unilocular and rich with hundreds to thousands of protoscolices; the morphology of $E$. multilocularis cysts differs, with masses of numerous small cysts interconnected by dense connective tissue [32-33]. The cysts consist of an inner germinal and nucleated syncytial layer supported externally by a carbohydrate-rich acellular laminated layer of variable thickness, which is surrounded by a host-produced fibrous adventitial layer [31, 38-39]. Daughter cysts may develop within larger primary cysts. Protoscolices (or protoscolex in E. multilocularis) are the preceding step before the adult worm when reuniting with the definitive host's intestine [38-39].

\section{Clinical Features and Diagnosis}

Pulmonary echinococcosis has been described in about $20 \%$ of infected patients, and the lungs are the second target organ after the liver, which is affected in about 70\% of cases reported [4]. Most of 
the infections in both lungs and liver are due to Echinococcus granulosus sensu lato complex, unlike E. multilocularis, in which almost all primary lesions are found in the liver [37]. Most patients have single-organ involvement with solitary cysts (cysts range from 1 to more than $20 \mathrm{~cm}$ in diameter), but $10 \%$ to $15 \%$ of patients have two or more involved organs [5]. Lungs are affected by multiple cysts in $20 \%$ to $30 \%$ of patients and are frequently located in the lower lobes, more often posteriorly than anteriorly and more often in the right lobes (approximately $50 \%$ have occurred in the right lung) $[4-5,40]$. Subjects with pulmonary echinococcosis are usually children or young adults (20 to 40 years old): in these high-risk groups, lungs may be involved in 50\% of Echinococcus spp. infections [41-42].

Pulmonary disease may be classified into three main clinical scenarios: asymptomatic early phase, symptomatic stage and complicated late phase.

\section{Asymptomatic early phase}

The early stages of CE and AE usually do not cause symptoms, and CE cysts and AE lesions can remain undetected for 10 to 15 years [4-5]. Children and young adults are often asymptomatic despite the presence of large lesions, probably because of anatomical features such as higher elasticity of the lung parenchyma and the rib cage and weaker immune response against parasites [41-43]. Subclinical or late-presenting symptoms are typical for most AE and CE patients because of the slow annually growth of cysts (ranging from 1 to $5 \mathrm{~cm}$ per year), especially in immunocompetent patients [4-5, 40]. The faster growth of cysts in CE patients with AIDS suggests that immune suppression may play a role in CE progression [30]. Genetic variation of the human leukocyte antigen (HLA) system is associated with the occurrence or progression of AE lesions in humans; patients with the HLA-DR3 DQ2 haplotype were shown to have more severe disease and a more pronounced Th2-type immune response, associated with a more profound tolerance status $[30]$.

\section{Symptomatic Stage}

Various symptoms are loco-regional and may be due to compression or damage to bronchia, vessels, rib cage or mediastinal organs: most symptoms of pulmonary CE are caused by mass effect exerted by the cysts on nearby tissues [44-45]. Cough, chest pain, dyspnea and hemoptysis are the most common symptoms reported [4-5, 46-47]. Less frequent are malaise, nausea, vomiting and thoracic deformations [4-5, 46-47]. Most pulmonary cysts are located in the lower lobes, more often posteriorly than anteriorly [48]. Approximately 50\% of cysts are localized in the right lung, 40\% in the left lung, and $10 \%$ bilaterally [48-49]. 


\section{Late Complicated Stage}

The presence of any complications changes the clinical presentation, either causing new symptoms or increasing the severity of existing symptoms.

The main complication is cyst rupture; in any organ, cyst rupture can induce fever, urticaria, eosinophilia and anaphylactic shock [50]. Lung cysts may break, causing cyst material containing fragments of larval tissue and protoscolices to be spilt and eventually flow either into the bronchial tree, producing cough, chest pain, hemoptysis or vomica [51], or into the pleural cavity, causing simple or tension pneumothorax, pleural effusion or empyema [52]. Mediastinal cysts may erode into adjacent structures, causing bone pain, haemorrhage or airflow limitation [53-54]. Eosinophilia and allergic reactions are very uncommon in $\mathrm{AE}$ because of the different structure of the parasitic lesions from CE, with dense fibrosis preventing vesicle fluid leakage; these reactions may be observed in rare cases of dissemination of lesion fragments into the blood [55-57]. Other potential clinical effects of hydatid infection include immune complex-mediated disease, glomerulonephritis leading to nephrotic syndrome [58], and secondary amyloidosis [59]. Another significant complication is the superinfection of the cyst, manifesting as a pulmonary abscess with poorly defined margins. Ruptured cysts may become infected with bacteria or with saprophytic or invasive fungi, which are serious complications [60-63]. Hydatid disease causes recurrent acute pulmonary embolism in rare cases [64]. Transdiaphragmatic migration of hydatid disease from the posterior segments of the right hepatic lobe has been reported to be a common complication and is probably related to their proximity to the diaphragm [65].

\section{Diagnosis}

\section{Radiological diagnosis}

The first step in assessing lung hydatidosis is taking a chest X-ray [66]. Uncomplicated cysts appear on chest radiographs as a rounded or ovalized masses with smooth borders and uniform density and are surrounded by healthy lung tissue [67]. Indirect signs of lung hydatidosis on close structures (e.g., trachea, bronchi) are visible if the dimensions of cysts are relevant, such as a shift of the mediastinum, pleural reactions or compression of the lung parenchyma causing atelectasis [67-68]. X-rays can easily detect calcification of pulmonary cysts, but it is rare to find calcification in pulmonary echinococcosis [68-69]. Complicated cysts, such as broken cysts, present with typical diagnostic but also different signs [67-69]. Typical signs with variable frequencies between case series are visible in X-rays. The crescent or meniscus sign occurs as a result of air introduced between the pericyst and the exocyst, causing the erosion of bronchioles for cyst growth: some authors consider it as an 
alarming sign of impending rupture [30, 67-69]. The ingress of air within the cyst may also appear as parallel arches of air with an appearance like an onion peel, which is called Cumbo's sign. [30, 6768]. The presence of an air/fluid level may be interpreted as a theoretical communication between the cyst and the tracheobronchial tree [30, 67-68]. The water lily or Camelotte sign follows the collapse of the entire endocyst, in which the crumpled internal layer floats freely in the cyst fluid [30]. The fluid component might be expelled in the tracheobronchial tree, and the remaining solid component of the cyst gives rise to a mass within a cavity, or Monod's sign [67-69].

A CT scan is useful to better identify specific details of the lesions and their surrounding structures, helping to exclude alternative differential diagnoses: in intact cysts, a CT scan may reveal a thin rim defining the perimeter [48]. Small cysts, undetectable by a chest X-ray, may be detected with CT scanning's better imaging definition, which is also valuable in the case of complicated cysts; for example, it can identify a cyst wall defect in a ruptured cyst [70]. Infected cysts show in CT scans as poorly defined masses with increased internal density and contrast enhancement around the cyst wall (the ring enhancement sign) after the injection of a contrast substance. CT scanning can elucidate the cystic nature of the lung mass and provide accurate localization to plan the surgical treatment of complicated cysts [70-71].

Ultrasonography is helpful in most cases, providing excellent images only when the cysts are close to the pleural surface [72]. Most importantly, however, ultrasound examination of the liver may reveal concomitant liver involvement in up to $15 \%$ of individuals with lung $\mathrm{CE}$ [73]. Contrast-enhanced ultrasonography, based on pulsating blood flow imaging, may be used to detect small AE lesions and differentiate them from abscesses and tumours [72-73].

With magnetic resonance imaging (MRI), cysts show low signal intensity in T1-weighted images and high signal intensity in T2-weighted images: signal characteristics of a hydatid cyst may differ depending on the developmental phase [67-68]. FDG-positron emission tomography (FDG-PET) has become the favoured reference tool to evaluate their metabolic activity [74]. In CE, MRI appears to be of better diagnostic value than CT scanning, and both procedures are complementary to AE and should be performed to provide sufficient information for therapeutic decision-making [67-68].

\section{Serological diagnosis}

Major antigens for immunodiagnosis are contained in the hydatid fluid [75]. In the past, the Casoni intradermal test has exhibited low specificity and sensitivity; furthermore, poor standardization and ethical issues regarding the injection of reagents of animal origin into humans have considerably limited the use of skin tests for echinococcosis diagnosis [76]. Reported sensitivities of serological 
methods for testing CE patients, confirmed by surgical resection, vary from $60 \%$ to $90 \%$ [75, 77-78]. The encystment of the metacestode prevents the stimulation of antibody-producing cells, which could induce false-negative results of serology tests [75, 77-78].

For both $\mathrm{CE}$ and $\mathrm{AE}$, serology is now used only to confirm imaging results; it may also provide some insight into the infection pressure on a given population (e.g., children) in a particular geographic area [77-78]. The Expert Consensus of the WHO-IWGE also uses serology results to determine "possible" and "probable" cases [79].

\section{Treatment}

A uniform treatment regimen or approach may not be feasible because of the variability of pulmonary echinococcosis. No clinical trials have compared all the different treatment modalities. Cyst size, characteristics, position in the lung and clinical presentation and the availability of medical/surgical expertise and equipment are the mainstays of echinococcosis management . Many patients with lung lesions were admitted to hospital because of complications, mainly infection.

\section{Surgical approach}

The aim of surgical treatment of hydatid cysts is the complete evacuation of the cyst, the removal of the endocyst to avoid intraoperative contamination, the closure of the pericystic cavity to prevent prolonged air leak and empyema and the preservation of healthy lung parenchyma [80-82]. All the abovementioned precautions should be taken perioperatively to avoid accidental rupture of the cyst. If anaphylactic shock occurs as a result of cyst rupture, steroids and octreotide infusion must be administered [80-81].

For the removal of the cyst, different surgical techniques may be considered. The Ugon enucleation technique was proposed in 1952 and is suitable for a relatively small cyst. The surrounding area is fixed with packs soaked in a scolicidal agent (povidone iodine or hypertonic saline). An incision is made over the adventitia layer of the cyst to observe the underlying white-coloured laminated membrane [81-83]. The anaesthetist is then asked to apply positive pressure ventilation to the ipsilateral lung. This manoeuvre should cause the cyst to be expelled intact from the cavity. The remaining cyst cavity is irrigated with an isotonic saline solution, and air leaks are obliterated using non-absorbable stitches [81].

Cystotomy with capitonnage (Barrett's method) was proposed in 1952. The enucleation step involves careful incision of the lung parenchyma, avoiding rupture of the cyst. The cyst is carefully dissected with blunt dissection and positive pressure ventilation, which assists the enucleation process. The cavity walls are approximated with either interrupted non-absorbable purse-string 
sutures or the walls of the cyst. Finally, the healthy parenchymal ends are approximated with nonabsorbable sutures [80-82].

Posadas' method is a modification of Barrett's procedure and consists of the closure of the airway openings before capitonnage. The Perez-Fontana method of pericystectomy was proposed in 1953, and it involves excising the hydatid cyst along with the pericyst, which is adhered to the normal lung parenchyma [82]. There is now a consensus that the host tissue generates the pericyst in response to the cyst, and there is no need to remove it, mainly because its excision leads to a more prolonged air leak.

The needle aspiration method (the Figuera technique) entails no risk of cyst rupture or contamination of the pleura [80-81]. To prevent contamination, a few towels soaked in povidoneiodine solution are placed around the cyst. The syringe and catheters are outside the chest cavity. Then the pericyst is incised with scissors, and the fluid within the cyst is aspirated. When the cyst is decompressed, the surrounding parenchyma is incised, and the endocyst is removed [81-83]. The air leaks are obliterated with absorbable sutures. Although parenchyma-sparing procedures are preferred, sometimes segmentectomy, lobectomy and even pneumonectomy are required. Lung resections for the treatment of hydatid cyst disease of the lung may be required in rare cases. In the literature, the rate of lobectomy ranges from $0.5 \%$ to $45 \%$ [80]. Indications for lobectomy are a large cyst involving more than $50 \%$ of the lung, a cyst complicated by suppurative pulmonary infection not responding to medical treatment, multiple unilobar cysts and parenchymal destruction and fibrosis of lung tissue in chronic cases [80-83].

The best surgical approach depends on the size of the cyst and whether the cyst is single or multiple, unilateral or bilateral, intact or ruptured and associated with a liver dome cyst or with destroyed lung parenchyma [81-83]. Commonly, thoracotomy is the selected approach for the resection of hydatid cysts of the lung. Besides, Median sternotomy is useful for the treatment of bilateral anterior hydatid cysts [80-82]. Moreover, the preferred surgical approach to liver cysts penetrating the diaphragm into the right lower or middle lobe is a standard thoraco-laparotomy. Nevertheless, in last years minimally invasive thoracoscopic approaches, named video-assisted thoracic surgery (VATS) (either, uniportal or multiportal), demonstrated to be a feasible and safe treatment strategy, especially for the treatment of small and peripheral cysts. [80-84]. Reported advantages of VATS 
were shorter surgical time, decreased length of hospital stay, lower experienced pain, and reduced surgical morbidity. [85-87] Almost Certainly, in the next future, those minimal invasive approaches, and probably also robotic-assisted surgery, will be more diffusively adopted for surgical treatment of lung hydatidosis, similarly as it occurs in lung cancer disease [88]. .

\section{Medical treatment}

Antiparasitic drug treatment may be a first definitive option or an adjunctive therapy following surgery [79]. Albendazole has proven to be the first choice for Echinococcus spp. infections, but an alternative option is mebendazole. Praziquantel is less effective but has been studied in combination with benzimidazoles.

Historically, variable periods (from two to four weeks) of anti-helminth chemotherapeutic agents are prescribed preoperatively to prevent disease recurrence due to spillage at the time after surgical treatment of liver hydatidosis, and albendazole plus praziquantel has been found to be superior in its scolicidal activity when compared with albendazole alone [89-90]. However, at this time, the efficacy of preoperative or post-operative therapy has not been clearly studied in pulmonary hydatidosis. As a convention, by translating evidence from liver hydatidosis studies, preoperative albendazole for two to four weeks is prescribed for preventing the post-operative regrowth ensuing on intra-operative spillage [89-91]. Despite that, the optimal duration of preoperative anti-helminths treatment in pulmonary echinococcosis remains unclear.

\section{Benzimidazoles}

Benzimidazoles may be the first option in small, uncomplicated lung cysts. The cut-off size for the diameter of lung lesions is not standardized, unlike for liver cysts, for which Albendazole (or Mebendazole) is suggested for diameters $<5 \mathrm{~cm}$ (CE1, WHO classification). Brunetti et al. [79], in an expert consensus, suggested that benzimidazoles should be avoided pre-operatively in larger lung cysts. A study [84] on the clinical experience of surgical therapy for thoracic hydatidosis reported an antiparasitic role of albendazole for multiple intrathoracic cysts (with or without liver lesions). Medical treatment is the preferred choice when surgery is not available or when complete removal is not feasible.

\section{Albendazole}


Albendazole (Table 1) is an anthelmintic benzimidazole carbamate given orally but poorly absorbed via this route of administration $(<5 \%)$ and, because of its insolubility, has not been administered parenterally [92]. In contrast with intestinal helminth species, for which drug absorption is not necessary, systemic parasites require an extended treatment to produce a sufficiently therapeutic drug [92-93]. Albendazole sulfoxide, the main metabolite of albendazole, is the main agent in systemic infections, with an elimination half-life of 8-12 hours, and it is moderately bound to plasma proteins (70\%) [92-93]. Albendazole acts first through the inhibition of parasite beta-tubulin polymerization and, second, through downstream effects, such as fumarate reductase inhibition and the interruption of energy pathways that result in parasite death [92].

Culture and in-vitro tests of the susceptibility of helminths to albendazole are often impossible, and anti-parasitic activities have been extrapolated by empirical testing in vivo in humans or by extrapolation from the doses used for domestic animal species [93].

In humans, definitive evidence of clinical resistance is lacking, but for Echinococcus spp., prolonged infections and intermittent treatment with anti-helminthic drugs might provide ideal circumstances for the development of resistance. On the other hand, transmission to other individuals would not occur as human infection represents a dead end for the parasite life cycle [93].

Albendazole presents a hepatic metabolism, but there is a lack of information about dose adjustment in liver impairment. [93-94]. Cotting et al. [95] presented five patients with echinococcosis and significant extrahepatic biliary obstruction, for whom the absorption and clearance of albendazole were significantly delayed and $\mathrm{C}_{\max }$ was doubled. Albendazole diffuses well in various tissues and has been detected in urine, bile, liver, cyst walls, cyst fluid and cerebrospinal fluid and is highly correlated with drug's concentrations in plasm [93-94].

\section{Mebendazole}

Mebendazole (Table 1) belong to the same anthelmintic class as albendazole, which has now largely replaced albendazole for Echinococcus infections. Its oral bioavailability is near 5-10\%, but with tracer doses of $[3 \mathrm{H}]$-mebendazole administered orally and intravenously, the absolute bioavailability was estimated to be $22 \%$ [96].

There are no clinical data on dose adjustment in renal impairment. Even with renal impairment, mebendazole is largely metabolized in the liver, so dose adjustment is not likely to be required in most cases [97]. Nevertheless, some authorities have advised caution during long-term therapy in patients with hepatic echinococcosis because metabolism may be impaired in such patients, leading to elevated levels of the parent drug and possible toxicity [96]. Moreover, plasma concentrations were 
reported to be higher in a patient with cholelithiasis than in normal subjects [97-98]. The metabolites are excreted principally in the urine, and in patients receiving long-term, high-dose of mebendazole, metabolites might accumulate [98-99].

Mebendazole can be measured in a number of tissues, most notably the liver, and in echinococcal cysts, where the concentrations correlated well with the free mebendazole plasma concentrations four hours after dosing [100]. There is significant interindividual variability in the bioavailability and metabolism of mebendazole, and there is little data to directly correlate the clinical activity of mebendazole with its pharmacokinetic and pharmacodynamic parameters [101].

\section{Praziquantel}

Praziquantel (Table 1) is a pyrazinoisoquinoline derivative found to be active against a wide range of trematode and cestode helminths [102]. Praziquantel is currently the mainstay treatment for schistosomiasis and opisthorchiasis. Its absorption after oral administration is up to $80 \%$, and it has almost total renal excretion. Its short plasma half-life requires administration three times per day [102-103].

Monotherapy with praziquantel has no activity against cystic echinococcosis. A small trial combining praziquantel and albendazole for six months resulted in a superior rate of cyst disappearance (47.4\% vs. $36.4 \%$ ) for up to three years, compared to 22 historical controls, which received albendazole alone [104]. This observation remains to be confirmed. In vitro and in vivo praziquantel theoretically has a role as a protoscolicide in preventing the dissemination of cyst content [105].

It is of note that praziquantel has a well-recognized effect on the pharmacokinetics of albendazole, increasing serum and intracyst concentrations of albendazole sulfoxide by inhibiting hepatic catabolism [106]. The relevance of this observation to clinical efficacy has yet to be established.

\section{Conclusions}

There is a growing tendency to manage uncomplicated cysts according to one of the main treatment options (e.g. watch and wait, surgical treatment, medical treatment, or both medical and surgical treatment) notably on the basis of host factors, comorbidities and cyst stage, size and location. Medical treatment (alone or combined) is the preferred choice when surgery is not available or when complete removal is not feasible [107]: in our opinion, antiparasitic drugs may be valuable in three specific instances: 1) in single, small, uncomplicated cysts, 2) in disseminated diseases or 3) patients with poor surgical risk. The cyst may be disrupted by medical therapy, but membranes associated with cysts carry a significant risk of infection. [108-109]. 
For pulmonary hydatidosis, surgery remains indicated in most cases: operative mortality remains acceptable (1-2\%), and morbidity is low [109-110]. The recurrence rate varies from $1.9 \%$ to $2.9 \%$, depending on the series [109-111].

A standard of care has not been widely endorsed or implemented outside referral centres because of a lack of well-designed clinical trials to respond to this need and to consolidate the best practices for treating hydatidosis (Figure 2). Complicated cysts require a case-by-case decision for appropriate management [108-110]. In support of surgical management, alongside the removal of the parasite, surgery may also act on associated parenchymal, bronchial, or pleural damage. Nevertheless, surgery must be as conservative as possible; resection is proposed only for severe and irremediable lung damage, and lobectomy is necessary in less than $10 \%$ of the patients [111-112]. Proper management of hydatidosis may also be considered from an infection control perspective. Monitoring the transmission of Echinococcus spp. has a pivotal role in public health, and efforts should be focused on strengthening and improving control programs in endemic areas to reduce the incidence and burden of echinococcosis [113-114].

In conclusion, hydatidosis management must become less heterogeneous. We support treatment targeted to the individual on the basis of the clinical situation, host factors and surgical risk. Strict cooperation in this process between infectious disease specialists and surgeons may optimise best practices to help create shared practical guidelines to simplify clinicians' decision-making.

Reprint requests to: Tommaso Lupia, MD; Department of Medical Sciences, Infectious Diseases, University of Turin, Italy; Email: tommaso.lupia89@gmail.com

Acknowledgements: none

\section{Authors disclosure statement:}

Funding: none

Conflicts of interest/Competing interests: none 
Availability of data and material (data transparency): not applicable

Code availability (software application or custom code): not applicable

\section{References}

1. Santivanez S, Garcia HH. Pulmonary cystic echinococcosis. Current Opinion in Pulmonary Medicine. 2010 May;16(3):257-261. DOI: 10.1097/MCP.0b013e3283386282.

2. Wen $H$, Vuitton L, Tuxun $T$ et al. Echinococcosis: advances in the 21 st century. Clin Microbiol Rev. 2019 Feb 13;32(2). pii: e00075-18. doi: 10.1128/CMR.00075-18. Print 2019 Mar 20

3. Deplazes P, Rinaldi L, Alvarez Rojas CA et al. Global Distribution of Alveolar and Cystic Echinococcosis. Adv Parasitol. 2017;95:315-493. doi: 10.1016/bs.apar.2016.11.001. Epub 2017 Jan 20. Review 
4. Morar R, Feldman C. Pulmonary echinococcosis. Eur Respir J. 2003 Jun;21(6):1069-77.

5. Gottstein B1, Reichen J. Hydatid lung disease (echinococcosis/hydatidosis). Clin Chest Med. 2002 Jun;23(2):397-408, ix.

6. Craig PS, McManus DP, Lightowlers MW et al. Prevention and control of cystic echinococcosis, Lancet Infect Dis. 2007 Jun;7(6):385-94.

7. Eckert J, Thompson RC. 2017. Historical aspects of echinococcosis. Adv Parasitol. 2017;95:164. doi: 10.1016/bs.apar.2016.07.003. Epub 2016 Sep 29

8. Debourgogne A, Blanchet D, Fior A et al. Neotropical echinococcosis caused by Echinococcus vogeli in a 6-year-old child: the second case report in humans in French Guiana. Paediatr Int Child Health. 2017 Feb;37(1):63-65. doi: 10.1179/2046905515Y.0000000054.

9. Knapp J, Chirica M, Simonnet C et al. Echinococcus vogeli infection in a hunter, French Guiana. Emerg Infect Dis. 2009 Dec;15(12):2029-31. doi: 10.3201/eid1512.090940

10. Romig T, Deplazes P, Jenkins D et al. Ecology and Life Cycle Patterns of Echinococcus Species. Adv Parasitol. 2017;95:213-314. doi:10.1016/bs.apar.2016.11.002. Epub 2017 Jan 6.

11. Thompson RC, Lymbery AJ. The nature, extent and significance of variation within the genus Echinococcus. Adv Parasitol. 1988;27:209-58.

12. Rossi P, Tamarozzi F, Galati F et al., The first meeting of the European Register of Cystic Echinococcosis (ERCE). Parasit Vectors. 2016 Apr 28;9:243. doi: 10.1186/s13071-016-1532-3

13. HERACLES collaborative project (Human cystic Echinococcosis ReseArch in CentraL and Eastern Societies).http://www.heracles-fp7.eu/

14. Torgerson PR, Devleesschauwer B, Praet N et al. World Health Organization Estimates of the Global and Regional Disease Burden of 11 Foodborne Parasitic Diseases, 2010: A Data Synthesis. PLoS Med. 2015 Dec 3;12(12):e1001920. doi: 10.1371/journal.pmed.1001920. eCollection 2015 Dec.

15. Zhang W, Zhang Z, Wu W et al. Epidemiology and control of echinococcosis in central Asia, with particular reference to the People's Republic of China. Acta Trop. 2015 Jan;141(Pt B):23543. doi: 10.1016/j.actatropica.2014.03.014. Epub 2014 Mar 28.

16. Craig PS, Li T, Qiu J et al. Echinococcosis and Tibetan communities. Emerg Infect Dis. 2008 Oct;14(10):1674-5. doi: 10.3201/eid1410.071636

17. Larrieu E, Zanini F. Critical analysis of cystic echinococcosis control programs and praziquantel use in South America, 1974-2010. Rev Panam Salud Publica. 2012 Jan;31(1):81-7.

18. Pavletic CF, Larrieu E, Guarnera EA et al. Cystic echinococcosis in South America: a call for action. Rev Panam Salud Publica. 2017 Aug 21;41:e42. 
19. Cucher MA, Macchiaroli N, Baldi G et al., Cystic echinococcosis in South America: systematic review of species and genotypes of Echinococcus granulosus sensu lato in humans and natural domestic hosts. Trop Med Int Health. 2016 Feb;21(2):166-75. doi: 10.1111/tmi.12647. Epub 2015 Dec 28

20. Jenkins DJ, Lievaart JJ, Boufana B, Lett WS, Bradshaw H, Armua Fernandez MT. 2014. Echinococcus granulosus and other intestinal helminths: current status of prevalence and management in rural dogs of eastern Australia. Aust Vet J. 2014 Aug;92(8):292-8. doi: 10.1111/avj. 12218

21. Deplazes P, Gottstein B, Junghanss T. Alveolar and cystic echinococcosis in Europe: Old burdens and new challenges., Vet Parasitol. 2015 Oct 30;213(3-4):73-5. doi: 10.1016/j.vetpar.2015.08.001. Epub 2015 Aug 4

22. Moro P, Schantz PM. Cystic echinococcosis in the Americas. Parasitol Int. 2006;55 Suppl:S1816. Epub 2005 Dec 22

23. Torgerson PR, Keller K, Magnotta M et al. The global burden of alveolar echinococcosis. PLoS Negl Trop Dis. 2010 Jun 22;4(6):e722. doi: 10.1371/journal.pntd.0000722

24. Baumann S, Shi R, Liu W et al. Worldwide literature on epidemiology of human alveolar echinococcosis: a systematic review of research published in the twenty-first century. Infection. 2019 Oct;47(5):703-727. doi: 10.1007/s15010-019-01325-2. Epub 2019 May 30.

25. Usubalieva J, Minbaeva G, Ziadinov I, Deplazes P, Torgerson PR. Human alveolar echinococcosis in Kyrgyzstan. Emerg Infect Dis. 2013 Jul;19(7):1095-7. doi: 10.3201/eid1907.121405.

26. Schneider R, Aspöck H, Auer H. Unexpected increase of alveolar echinococcosis, Austria, 2011 Emerg Infect Dis. 2013 Mar;19(3):475-7. doi: 10.3201/eid1903.120595

27. Charbonnier A, Knapp J, Demonmerot F et al. A new data management system for the French National Registry of human alveolar echinococcosis cases. Parasite. 2014;21:69. doi: 10.1051/parasite/2014075. Epub 2014 Dec

28. Schmidberger J, Kratzer W, Stark K, Grüner B, Echinococcosis Working Group. Alveolar echinococcosis in Germany, 1992-2016. An update based on the newly established national AE database. Infection. 2018 Apr;46(2):197-206. doi: 10.1007/s15010-017-1094-0. Epub 2017 Oct 31

29. Schweiger A, Ammann RW, Candinas D, Clavien PA, Eckert J, Gottstein B, et al. Human alveolar echinococcosis after fox population increase, Switzerland. Emerg Infect Dis. 2007 Jun;13(6):87882. 
30. Massolo A, Liccioli S, Budke C et al. Echinococcus multilocularis in North America: the great unknown. Parasite. 2014;21:73. doi: 10.1051/parasite/2014069. Epub 2014 Dec 23

31. Eckert J \& Deplazes P Biological, Epidemiological and Clinical Aspects of Echinococcosis, a Zoonosis of Increasing Concern, Clinical Microbiology Reviews, Jan. 2004, p. 107-135

32. Raoul, F., P. Deplazes, N. Nonaka, R. Piarroux, D. A. Vuitton, and P.Giraudoux. 2001. Assessment of the epidemiological status of Echinococcus multilocularis in foxes in France using ELISA coprotests on fox feces collected in the field. Int. J. Parasitol. 31:1579-1588. 155.

33. Rausch, R. L. 1995. Life cycle patterns and geographic distribution of Echinococcus species, p. 88-134. In R. C. A. Thompson and A. J. Lymbery (ed.), Echinococcus and hydatid disease. CAB International, Wallingford, United Kingdom.

34. Schantz P. Echinococcosis. In: Guerrant R, Walker DH, Weller PF, eds. Tropical Infectious Diseases:

Principles,

Pathogens and Practice. Philadelphia, WB Saunders, 1999; pp. 1005-1025.

35. King CH. Cestodes (tapeworms). In: Mandell GL, Bennett JE, Dolin R, eds. Principles and Practice of Infectious Diseases. New York, Churchill Livingstone, 1995; pp. 2544-2553.

36. Ammann RW, Eckert J. Cestodes. Echinococcus. Gastroenterol Clin North Am 1996; 25: 655689.

37. Kammerer WS, Schantz PM. Echinococcal disease. Infect Dis Clin North Am 1993; 7: 605-618.

38. Eckert, J., and R. C. A. Thompson. 1997. Intraspecific variation of Echinococcus granulosus and related species with emphasis on their infectivity to humans. Acta Trop. 64:19-34

39. Thompson, R. C. A. 1995. Biology and systematics of Echinococcus, p. 1-50. In R. C. A. Thompson and A. J. Lymbery (ed.), The biology of Echinococcus and hydatid disease. CAB International, Wallingford, United Kingdom

40. Ozhan MH. Pulmonary hydatidosis: state of the art. Int Arch Hydatidosis 2001;34:11- 2

41. Arroud M, Afifi MA, El Ghazi K, et al. Lung hydatic cysts in children: comparison study between giant and non-giant cysts. Pediatr Surg Int. 2009; 25:37-40. [PubMed: 18828025]

42. Torgerson PR, Deplazes P. Echinococcosis: diagnosis and diagnostic interpretation in population studies. Trends Parasitol. 2009; 25:164-170. [PubMed: 19269248]

43. Rebhandl W, Turnbull J, Felberbauer FX, Tascl E, Puig S, Auer H, et al. Pulmonary echinococcosis (hydatidosis) in children: results of surgical treatment. Pediatr Pulmonol 1999;27:336- 40 .

44. Turgut AT, Altinok T, Topcu S, Kosar U. Local complications of hydatid disease involving thoracic cavity: imaging findings. Eur J Radiol. 2009; 70:49-56. [PubMed: 18291609] 
45. Dziri C, Haouet K, Fingerhut A, Zaouche A. Management of cystic echinococcosis complications and dissemination: where is the evidence? World J Surg. 2009; 33:1266-1273. [PubMed:19350321]

46. Arinc S, Kosif A, Ertugrul M, et al. Evaluation of pulmonary hydatid cyst cases. Int J Surg. 2009;7:192-195. [PubMed: 19369124]

47. Dopchiz MC, Elissondo MC, Andresiuk MV, et al. Pediatric hydatidosis in the south-east of the Buenos Aires province, Argentina. Rev Argent Microbiol. 2009; 41:105-111. [PubMed: 19623901]

48. Kervancioglu R, Bayram M, Elbeyli L. CT findings in pulmonary hydatid disease. Acta Radiol 1999;40:510-4.

49. Ramos G, Orduna A, Garcia-Yuste M. Hydatid cyst of the lung: diagnosis and treatment. World J Surg 2001; 25:46-57.

50. Xanthakis DS, Katsaras E, Efthimiadis M, Papadakis G, Varouchakis G, Aligizakis C. Hydatid cyst of the liver with intrathoracic rupture. Thorax 1981; 36: 497-501.

51. Jerray M, Benzarti M, Garrouche A, Klabi N, Hayouni A. Hydatid disease of the lungs: study of 386 cases. Am Rev Respir Dis 1992; 146: 185-189.

52. Aribas OK, Kanat F, Gormus N, Turk E. Pleural complications of hydatid disease. J Thorac Cardiovasc Surg 2002; 123: 492-497.

53. Rakower J, Milwidsky H. Primary mediastinal echinococcosis. Am J Med 1960; 29: 73-83.

54. Ozdemir N, Akal M, Kutlay H, Yavuzer S. Chest wall echinococcosis. Chest 1994; 105: 12771279.

55. Lewall DB, McCorkell SJ. Rupture of echinococcal cysts: diagnosis, classification, and clinical implications. AJR Am J Roentgenol 1986; 146: 391-394.

56. Giulekas D, Papacosta D, Papaconstantinou C, Barbarousis D, Angel J. Recurrent anaphylactic shock as a manifestation of echinococcosis: report of a case. Scand J Thorac Cardiovasc Surg 1986; 20: 175-177.

57. Solak H, Ceran S, Ozpinar C, et al. Lung hydatid cyst rupture and its surgery. Indian J Med Sci 1994; 48: 155-157.

58. Gelman R, Brook G, Green J, Ben-Itzhak O, Nakhoul F. Minimal change glomerulonephritis associated with hydatid disease. Clin Nephrol 2000; 53: 152-155.

59. Ali-Khan Z, Rausch RL. Demonstration of amyloid and immune complex deposits in renal and hepatic parenchyma of Alaskan alveolar hydatid disease patients. Ann Trop Med Parasitol 1987; 81: 381-392. 
60. Kini U. Invasive mycosis of a pulmonary hydatid cyst in a non-immunocompromised host. J Trop Med Hyg 1995; 98: 404-406.

61. Date A, Zachariah N. Saprophytic mycosis with pulmonary echinococcosis. J Trop Med Hyg 1995; 98: 416-418.

62. García MB, Lledías JP, Pérez IG et al., Primary super-infection of hydatid cyst--clinical setting and microbiology in 37 cases. Am J Trop Med Hyg. 2010 Mar;82(3):376-8. doi: 10.4269/ajtmh.2010.09-0375.

63. Engström ELS, Salih GN, Wiese L. Seronegative, complicated hydatid cyst of the lung: A case report. Respir Med Case Rep. 2017 Apr 10;21:96-98. doi: 10.1016/j.rmcr.2017.04.005. eCollection 2017.

64. Lioulias A, Kotoulas C, Kokotsakis J, Konstantinou M. Acute pulmonary embolism due to multiple hydatid cysts. Eur J Cardiothorac Surg 2001; 20: 197-199.

65. Arıbaş BK, Dingil G, Köroğlu M et al. Liver hydatid cyst with transdiaphragmatic rupture and lung hydatid cyst ruptured into bronchi and pleural space. Cardiovasc Intervent Radiol. 2011 Feb;34 Suppl 2:S260-5. doi: 10.1007/s00270-009-9734-0. Epub 2009 Oct 22.

66. Brunetti E, Kern P, Vuitton DA. 2010. Expert consensus for the diagnosis and treatment of cystic and alveolar echinococcosis in humans. Acta Trop 114:1-16. https://doi.org/10.1016/j.actatropica.2009.11.001.

67. Pedrosa I, Saíz A, Arrazola J, Ferreirós J, Pedrosa CS. Hydatid disease: radiologic and pathologic features and complications. Radiographics. 2000 May-Jun;20(3):795-817.

68. Loyarte HF, Gutman M. Review of the radiological manifestations in hydatid echinococcosis of the lung. Dia Med. 1959 May 28;31(34):884 passim.

69. Grünebaum M. Radiological manifestations of lung echinococcosis in children. Pediatr Radiol. 1975 Mar 20;3(2):65-9.

70. Kern P. 2010. Clinical features and treatment of alveolar echinococcosis. Curr Opin Infect Dis 23:505-512.https://doi.org/10.1097/QCO.0b013e32833d7516.

71. Graeter T, Kratzer W, Oeztuerk S, Haenle MM, Mason RA, Hillenbrand A, Kull T, Barth TF, Kern P, Gruener B. 2016. Proposal of a computed tomography classification for hepatic alveolar echinococcosis. World J Gastroenterol 22:3621-3631. ttps://doi.org/10.3748/wjg.v22.i13.3621.

72. Kratzer W, Gruener B, Kaltenbach TE, Ansari-Bitzenberger S, Kern P, Fuchs M, Mason RA, Barth TF, Haenle MM, Hillenbrand A, Oeztuerk S, Graeter T. 2015. Proposal of an Ultrasonographic classification for hepatic alveolar echinococcosis: Echinococcosis multilocularis Ulm classification ultrasound. World J Gastroenterol 21:12392-12402. https://doi.org/10.3748/wjg.v21.i43.12392. 
73. Song T, Qin Z, Hao W, Yongquan L, Lanhui Y, Lei Y. 2011. Usefulness of gray-scale contrastenhanced ultrasonography (SonoVue(R)) in diagnosing hepatic alveolar echinococcosis. Ultrasound Med Biol 37: 1024-1028. https://doi.org/10.1016/j.ultrasmedbio.2011.04.014.

74. Kumar NS, Barve K, Joshi J, Basu S. Incidental Diagnosis of an Asymptomatic Hydatid Cyst Through Low-Grade 18F-FDG Uptake in the Peripheral RimJ Nucl Med Technol. 2015 Dec;43(4):292-4. doi: 10.2967/jnmt.115.155408. Epub 2015 Jun 25.

75. Vola A, Tamarozzi F, Noordin R et al. Preliminary assessment of the diagnostic performances of a new rapid diagnostic test for the serodiagnosis of human cystic echinococcosis. Diagn Microbiol Infect Dis. 2018 Sep;92(1):31-33. doi: 10.1016/j.diagmicrobio.2018.04.007. Epub 2018 Apr 14.

76. Ray R, De PK, Karak K. 2002. Combined role of Casoni test and indirect haemagglutination test in the diagnosis of hydatid disease. Indian J Med Microbiol 20:79-82

77. Zhang W, Li J, McManus DP. 2003. Concepts in immunology and diagnosis of hydatid disease. Clin Microbiol Rev 16:18-36. https://doi .org/10.1128/CMR.16.1.18-36.2003.

78. Zhang W, Wen H, Li J, Lin R, McManus DP. 2012. Immunology and immunodiagnosis of cystic echinococcosis: an update. Clin Dev Immunol 2012:101895. https://doi.org/10.1155/2012/101895.

79. Brunetti E, Kern P, Vuitton DA; Writing Panel for the WHO-IWGE. Expert consensus for the diagnosis and treatment of cystic and alveolar echinococcosis in humans. Acta Trop. 2010 Apr;114(1):1-16. doi: 10.1016/j.actatropica.2009.11.001. Epub 2009 Nov 30.

80. Locicero J, Feins RH, Colson Y, Rocco G. General thoracic surgery. VIII edition

81. Halezeroglu S, Okur E, Tanyü O. Surgical Management for Hydatid Disease. Thorac Surg Clin 22 (2012) 375-385

82. Nabi MS, Waseem T. Pulmonary hydatid disease: What is the optimal surgical strategy? Internation Journal of Surgery 8 (2010) 612-616

83. Thapa B, Sapkota R, Kim M, Barnett SA, Sayami P. Surgery for parasitic lung infestations: roles in diagnosis and treatment. J Thorac Dis 2018;10(Suppl 28):S3446-S3457

84. Isitmangil T, Sebit S, Tunc H et al. Clinical experience of surgical therapy in 207 patients with thoracic hydatidosis over a 12-year-period. Swiss Med Wkly. 2002 Oct 12;132(37-38):548-52.

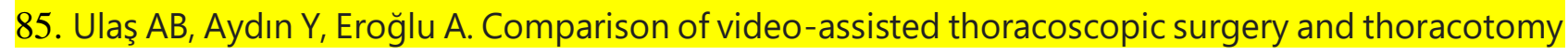
in the treatment of mediastinal cysts. Turk Gogus Kalp Damar Cerrahisi Derg. 2018;26(2):265-271. Published 2018 Apr 30. doi:10.5606/tgkdc.dergisi.2018.15233

86. Abu Akar F, Gonzalez-Rivas D, Shaqqura B, et al. Uniportal video assisted thoracoscopy versus open surgery for pulmonary hydatid disease-a single center experience. J Thorac Dis. 2020;12(3):794-802. doi:10.21037/jtd.2019.12.73 
87. Ma, J., Wang, X., Mamatimin, X. et al. Therapeutic evaluation of video-assisted thoracoscopic surgery versus open thoracotomy for pediatric pulmonary hydatid disease. J Cardiothorac Surg 11, 129 (2016). https://doi.org/10.1186/s13019-016-0525-9

88. Guerrera F, Olland A, Ruffini E, Falcoz PE. VATS lobectomy vs. open lobectomy for early-stage lung cancer: an endless question-are we close to a definite answer?. J Thorac Dis. 2019;11(12):5616-5618. doi:10.21037/jtd.2019.12.19

89. Taylor DH, Morris DL. Combination chemotherapy is more effective in postspillage prophylaxis for hydatid disease than either albendazole or praziquantel alone. Br. J. Surg. 1989; 76: 954.

90. Cobo F, Yarnoz C, Sesma B et al. Albendazole plus praziquantel versus Albendazole alone as a pre-operative treatment in intra-abdominal hydatisosis caused by Echinococcus granulosus. Trop. Med. Int. Health 1998; 3: 462-6

91. Aktan AO, Yalin R. Preoperative albendazole treatment for liver hydatid disease decreases the viability of the cyst. Eur. J. Gastroenterol. Hepatol. 1996; 8: 877-9

92. Marriner SE, Morris DL, Dickson B et al. Pharmacokinetics of albendazole in man. Eur J Clin Pharmacol. 1986;30(6):705-8.

93. Morris DL, Chinnery JB, Georgiou G et al., Penetration of albendazole sulphoxide into hydatid cysts. Gut. 1987 Jan;28(1):75-80.

94. Horton J. Albendazole: a broad spectrum anthelminthic for treatment of individuals and populations. Curr Opin Infect Dis. 2002 Dec;15(6):599-608.

95. Cotting J, Zeugin T, Steiger U, Reichen J. Albendazole kinetics in patients with echinococcosis: delayed absorption and impaired elimination in cholestasis Eur $\mathrm{J}$ Clin Pharmacol. 1990;38(6):605-8.

96. Dawson M, Braithwaite PA, Roberts MS, Watson TR. The pharmacokinetics and bioavailability of a tracer dose of [3H]-mebendazole in man. Br J Clin Pharmacol. 1985 Jan;19(1):79-86.

97. Edwards G, Breckenridge AM. Clinical pharmacokinetics of anthelmintic drugs. Clin Pharmacokinet. 1988 Aug;15(2):67-93.

98. Dayan AD. Albendazole, mebendazole and praziquantel. Review of non-clinical toxicity and pharmacokinetics. Acta Trop. 2003 May;86(2-3):141-59.

99. Münst GJ, Karlaganis G, Bircher J. Plasma concentrations of mebendazole during treatment of echinococcosis: preliminary results. Eur J Clin Pharmacol. 1980 May;17(5):375-8. 
100. Witassek F, Bircher J. Chemotherapy of larval echinococcosis with mebendazole: microsomal liver function and cholestasis as determinants of plasma drug level. Eur J Clin Pharmacol. 1983;25(1):85-90.

101. Luder PJ, Witassek F, Weigand K, Eckert J, Bircher J.Treatment of cystic echinococcosis (Echinococcus granulosus) with mebendazole: assessment of bound and free drug levels in cyst fluid and of parasite vitality in operative specimens. Eur J Clin Pharmacol. 1985;28(3):279-85.

102. Andrews P, Thomas H, Pohlke R, Seubert J. Praziquantel. Med Res Rev. 1983 AprJun;3(2):147-200.

103. King CH \& Mahmoud AAF: Drugs five years later: praziquantel.. Ann Intern Med 1989; 110(4):290-6.

104. Kaojarern S, Nathakarnkikool S, \& Suvanakoot U: Comparative bioavailability of praziquantel tablets. Drug Intell Clin Pharm 1989; 23:29-32.

105. Mohamed AE, Yasawy MI, Al Karawi MA. Combined albendazole and praziquantel versus albendazole alone in the treatment of hydatid disease. Hepatogastroenterology. 1998 SepOct;45(23):1690-4.

106. Bygott JM, Chiodini PL. Praziquantel: neglected drug? Ineffective treatment? Or therapeutic choice in cystic hydatid disease? Acta Trop. 2009 Aug;111(2):95-101. doi: 10.1016/j.actatropica.2009.04.006. Epub 2009 Apr 16.

107. McManus DP, Zhang W, Li J, Bartley PB. Echinococcosis. Lancet. 2003 Oct8;362(9392):1295-304. Review.

108. Ramos G, Orduna A, Garcia-Yuste M: Hydatid cyst of the lung: diagnosis and treatment. World J Surg 2001, 25:46-57

109. Kurul IC, Topcu S, Altinok T, et al. One stage operation for hydatid disease of the lung and liver: principles of treatment. J Thorac Cardiovasc Surg 2002; 124:1212

110. Keramidas D, Mavridis G, Soutis M, et al. Medical treatment of pulmonary hydatidosis: complications and surgical management. Pediatr Surg Int 2004; 19:774.

111. Topcu S, Kurul IC, Tastepe I, et al.: Surgical treatment of pulmonary hydatid cysts in children. J Thorac Cardiovasc Surg 2000, 120:1097-1101.

112. Cangir AK, Sahin E, Enon S, et al.: Surgical treatment of pulmonary hydatid cysts in children. J Pediatr Surg 2001, 36:917-920.

113. Vasquez JC, Montesinos E, Peralta J, et al. Need for lung resection in patients with ruptured hydatid cysts. Thorac Cardiovasc Surg 2009;57:295-302 
114. Halezeroglu S. Resection of intrathoracic and subdiapragmatic hydatid cysts. Multimed Man Cardiothorac Surg Available at: http://mmcts.ctsnetjournals.org/. Accessed 2004. DOI:

$10.1510 /$ mmcts.2004.000307

Figure 1: Lifecycle of Echinococcus granulosus between definitive, intermediate and accidental hosts

Figure 2: Tailored approach to lung hydatidosis according to size and number of cysts, features of cysts, host's features and surgical risk

Table 1: Main pharmacokinetics and pharmacodynamics features of Albendazole, Mebendazole and Praziquantel 